\title{
The dichotomy in carcinogenesis of the distal esophagus and esophagogastric junction: intestinal-type vs cardiac-type mucosa- associated adenocarcinoma
}

Elizabeth G Demicco ${ }^{1}$, Alton B Farris III ${ }^{1,2}$, Yoshifumi Baba ${ }^{3}$, Brian Agbor-Etang ${ }^{4}$, Kristin Bergethon ${ }^{1}$, Rajni Mandal ${ }^{1}$, Diane Daives ${ }^{4}$, Junya Fukuoka ${ }^{5}$, Michio Shimizu ${ }^{6}$, Dora Dias-Santagata ${ }^{1}$, Shuji Ogino ${ }^{3,7}$, A John Iafrate ${ }^{1}$, Henning A Gaissert ${ }^{4}$ and Mari Mino-Kenudson ${ }^{1}$

${ }^{1}$ Department of Pathology, Massachusetts General Hospital and Harvard Medical School, Boston, MA, USA; ${ }^{2}$ Department of Pathology, Emory University School of Medicine, Atlanta, GA, USA; ${ }^{3}$ Department of Medical Oncology, Dana-Farber Cancer Institute and Harvard Medical School, Boston, MA, USA; ${ }^{4}$ Thoracic Surgery, Massachusetts General Hospital and Harvard Medical School, Boston, MA, USA; ${ }^{5}$ Department of Pathology, Toyama Medical University, Toyama, Japan; ${ }^{6}$ Department of Pathology, Saitama Medical University, International Medical Center, Saitama, Japan and ${ }^{7}$ Department of Pathology, Brigham and Women's Hospital and Harvard Medical School, Boston, MA, USA

Adenocarcinoma of the distal esophagus and esophagogastric junction continues to rise in incidence. An intestinal metaplasia (Barrett esophagus)-dysplasia-carcinoma sequence induced by gastroesophageal reflux disease is well established. However, a significant number of adenocarcinomas in the vicinity of the esophagogastric junction are seen in the background of gastric/cardiac-type mucosa without intestinal metaplasia. Thus, the aim of this study was to investigate the role of Barrett esophagus (intestinal-type mucosa) in the classification and prognosis of tumors of the distal esophagus and esophagogastric junction. Clinicopathological and molecular characteristics were examined in 157 consecutively resected adenocarcinomas of the distal esophagus and esophagogastric junction and were compared between tumors arising in association with intestinal-type and cardiac-type mucosa. Intestinal-type mucosa-associated adenocarcinomas were more likely to be associated with younger age $(P=0.0057)$, reflux symptoms $(P<0.0001)$, proximal location $(P=0.0009)$, lower $T$ stage $(P<0.0001)$, fewer nodal metastases $(P=0.0001)$, absence of lymphatic $(P<0.0001)$, venous $(P=0.0060)$ or perineural $(P<0.0001)$ invasion. Histologically, intestinal-type mucosa-associated tumors were more likely to be low-grade glandular tumors $(P=0.0095)$ of intestinal or mixed immunophenotype $(P=0.015)$ and express nuclear $\beta$-catenin $(P=0.0080)$, whereas tumors arising in a background of cardiac-type mucosa were more frequently associated with EGFR amplification $(P=\mathbf{0 . 0 0 5 1})$. Five-year overall survival rate was significantly higher in patients with intestinal-type mucosa-associated tumors ( 28 vs $9 \%, P=0.0015$ ), although no survival benefit was seen after adjusting for potential confounders. Our findings support the theory that multiple distinct pathways of tumorigenesis exist in the vicinity of the esophagogastric junction, including one in which tumors arise from dysplastic intestinal metaplasia (intestinal pathway), and one potentially involving dysplasia of the cardiac-type mucosa (non-intestinal pathway). Additional studies are warranted to further clarify their pathogenesis and the molecular mechanisms involved. Modern Pathology (2011) 24, 1177-1190; doi:10.1038/modpathol.2011.77; published online 13 May 2011

Keywords: adenocarcinoma; Barrett esophagus; carcinogenesis; distal esophagus; esophagogastric junction; prognosis

Correspondence: Dr M Mino-Kenudson, MD, Department of Pathology, Massachusetts General Hospital and Harvard Medical School, 55 Fruit Street, Warren 122, Boston, MA 02114. USA.

E-mail: mminokenudson@partners.org

Part of this work was presented at the 2010 annual meeting of the United States and Canadian Academy of Pathology in Washington, DC, USA.

Received 13 December 2010; revised 14 March 2011; accepted 14 March 2011; published online 13 May 2011 
The incidence of adenocarcinoma of the distal esophagus and esophagogastric junction has increased sixfold within the past 40 years in the United States and Western Europe. ${ }^{1,2}$ A number of studies have sought to determine if the anatomic location of these increasingly prevalent tumors could be associated with specific characteristics predictive of clinical outcome. Although some investigators found differences in gender predilection, prognosis and potential etiology after separating carcinomas of the esophagogastric junction and distal esophagus based on their anatomical relationship to the esophagogastric junction, ${ }^{3-5}$ others emphasized their similarities, prognosis in particular. ${ }^{6,7}$ Owing to these similarities in anatomic location and prognosis, the 7th edition AJCC staging manual has changed its guidelines to subsume tumors of the esophagogastric junction into those of the esophagus. ${ }^{8}$

Other studies have suggested that the presence of intestinal metaplasia of the esophagus, that is, Barrett esophagus, has a greater impact on prognosis. Barrett esophagus is a preneoplastic precursor lesion of adenocarcinomas of the distal esophagus and esophagogastric junction ${ }^{9,10}$ and is found in association with approximately $60 \%$ of esophageal adenocarcinomas. ${ }^{11}$ Like Barrett esophagus, adenocarcinomas of the esophagus and esophagogastric junction are more frequently found in men over the age of 65 years, many of whom have a history of gastroesophageal reflux disease. ${ }^{12,13}$ Some authors have claimed that adenocarcinomas arising in association with Barrett esophagus (intestinaltype mucosa-associated adenocarcinomas) have a better prognosis than those arising in a background of gastric/cardiac-type mucosa (cardiac-type mucosa-associated adenocarcinomas). ${ }^{14,15}$ This has led to the assertion that intestinal-type mucosa-associated adenocarcinoma is biologically different from cardiac-type mucosa-associated adenocarcinoma. Nevertheless, some groups maintain that cardiac type-mucosa-associated adenocarcinomas are simply large tumors that have overgrown preexisting short-segment Barrett esophagus, rather than comprising a separate entity ${ }^{16}$ and that prognostic differences between intestinal-type and cardiac-type mucosa-associated adenocarcinomas are due to early detection of tumors on surveillance endoscopy. ${ }^{17}$

Histopathological parameters other than tumor depth and lymph node involvement have not been well studied to determine their utility as predictors of natural history or treatment outcome in patients with adenocarcinoma of the distal esophagus or esophagogastric junction. We therefore sought to investigate whether the classification of distal esophageal and esophagogastric junction tumors by the presence of Barrett esophagus could be substantiated with an analysis of histopathological phenotypes, immunophenotypes and molecular alterations previously reported to be prognostic biomarkers for adenocarcinomas of the esophagus and stomach, as well as the relevance of these factors in tumor prognostication.

\section{Materials and methods}

Acquisition of tissue specimens and clinical information were approved by the Institutional Review Board of the Massachusetts General Hospital, and performed in accordance with Health Insurance Portability and Accountability Act (HIPAA) regulations.

\section{Patient Population}

From a prospectively collected database, a series of 272 esophagectomies and esophagogastrectomies for adenocarcinoma performed between January 2000 and May 2008 were identified. Of those, patients treated with neoadjuvant chemotherapy and/or radiation therapy $(n=83)$, photodynamic therapy $(n=2)$ or endoscopic mucosal resection $(n=4)$ were excluded. Tumors were initially classified by anatomic site, using the Siewert classification system, one of the most commonly used anatomic classification systems for tumors of the esophagogastric junction. ${ }^{3,18,19}$ This system includes only tumors arising within $5 \mathrm{~cm}$ of the esophagogastric junction, and defines the anatomic esophagogastric junction as the site where the proximal gastric rugal folds terminate and the tubular esophagus begins. Type 1 tumors are those arising with their epicenter within $1-5 \mathrm{~cm}$ proximal to the esophagogastric junction, whereas type 3 arise within $2-5 \mathrm{~cm}$ distal to the esophagogastric junction, and are considered to represent tumors of the subcardia that have spread into the esophagogastric junction from below. Type 2 tumors, those with an epicenter between $1 \mathrm{~cm}$ proximal and $2 \mathrm{~cm}$ distal to the anatomic esophagogastric junction, are thought to represent true tumors of the esophagogastric junction. For the purpose of this study, the topographic-anatomic location of tumor epicenter was determined using a combination of findings on radiographic imaging, endoscopic examination, operative reports, gross measurements, gross photographs, where available, and microscopic examination (please refer to the following section). In cases where the landmarks were completely obliterated on both gross and microscopic examination, the gross description and photographs indicating the length of the tubular esophagus and the extent of tumor involvement of both tubular esophagus and stomach were used to determine epicenter. The tumors with an epicenter located in the gastric body/fundus $(n=2)$, subcardia (Siewert type $3, n=17$ ) or esophagus ( $>5 \mathrm{~cm}$ proximal to the esophagogastric junction, $n=7$ ) involving the esophagogastric junction were excluded. The remaining 157 cases formed our study group: these consisted of adenocarcinomas 
of the distal esophagus (Siewert type 1) and those of the esophagogastric junction (Siewert type 2).

Clinical information including demographics, presenting symptoms, preoperative diagnosis of Barrett esophagus (intestinal metaplasia of the esophagus confirmed by review of biopsies), surveillance for Barrett esophagus, operative methods, tumor recurrence and mortality was obtained by retrospective chart reviews. For the purpose of this study, the operative approaches were classified as: (1) Ivor-Lewis ('two-hole') esophagectomy or esophagogastrectomy (a two-stage procedure involving abdominal dissection, followed by thoracic resection); (2) thoraco-abdominal esophagectomy or esophagogastrectomy; and (3) transhiatal gastroesophagectomy.

\section{Histopathological Analysis and Tissue Microarray Construction}

After formalin fixation, the specimens were sectioned in the following manner. Tumors $3 \mathrm{~cm}$ or less in diameter were entirely submitted along with columnar-lined esophagus. In tumors greater than $3 \mathrm{~cm}$ in diameter, at least three sections of the tumor including at least one of the tumor to normal esophagus interface and at least one of the tumor to grossly uninvolved distal mucosa were sampled. In cases with no grossly visible mass, the entire columnar-lined esophagus was submitted. Uninvolved esophagogastric junction, if present, was also sampled for microscopic evaluation in all settings. The tissue blocks were fixed in $10 \%$ buffered formalin, embedded in paraffin and cut at $5 \mu \mathrm{m}$. Hematoxylin and eosin (H\&E)-stained slides of each case were evaluated for tumor size, depth of invasion (pT), nodal metastases (pN, in accordance with 7th AJCC tumor staging), presence of distant metastases (pM), presence of lymphovascular invasion, large vessel (venous) invasion, perineural invasion, histological grade (pG) and histomorphological features of tumor and the background mucosa (Barrett vs non-Barrett). Intestinal metaplasia was defined as the presence of goblet cells
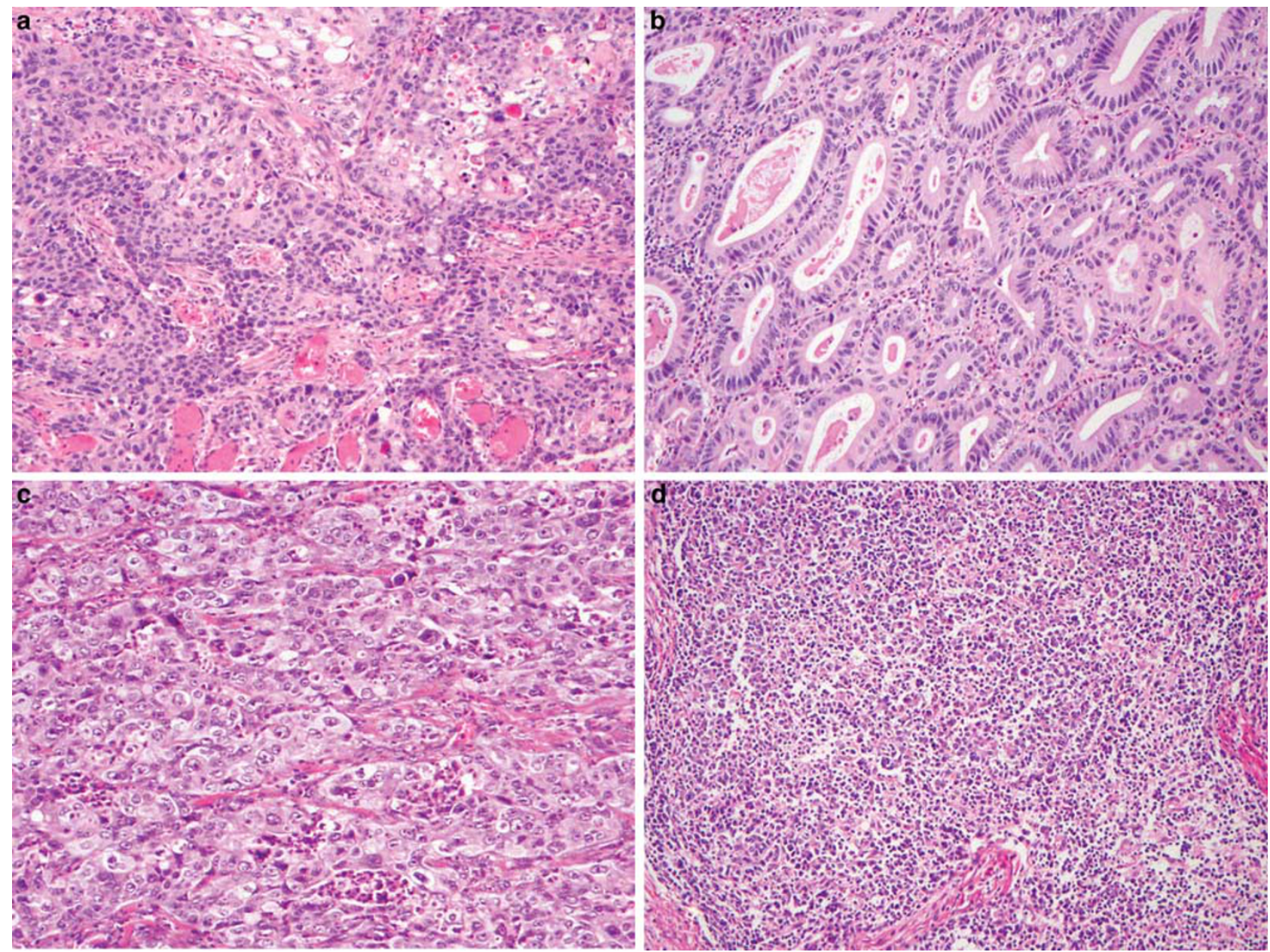

Figure 1 Histology and $\beta$-catenin immunostaining of adenocarcinomas of the esophagogastric junction. Examples of adenosquamous carcinoma (a), low-grade conventional adenocarcinoma (b), poorly differentiated adenocarcinoma (c), medullary carcinoma (d), mucinous carcinoma (e) and signet ring cell carcinoma (f). (g) Low-grade conventional adenocarcinoma with preserved membranous expression of $\beta$-catenin. (h) Poorly differentiated adenocarcinoma showing nuclear expression of $\beta$-catenin in $>10 \%$ of the tumor cells. In this example, cytoplasmic staining of $\beta$-catenin is also present, but membranous staining is completely lost in the vast majority of the tumor cells. 

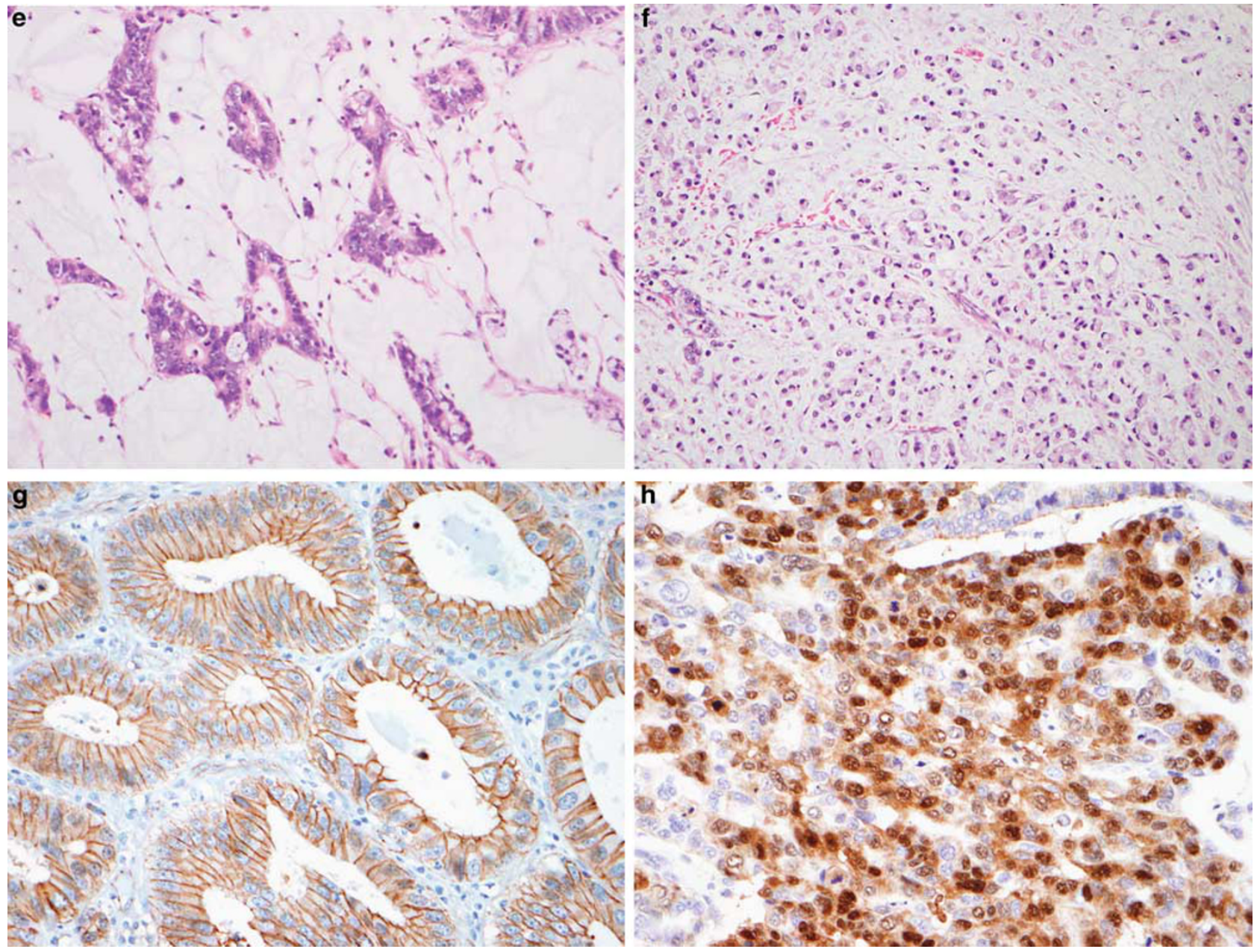

Figure 1 Continued.

within columnar epithelium. The esophageal location of intestinal metaplasia and/or carcinoma was confirmed histologically using the presence of submucosal glands and/or duplication of the muscularis mucosa as esophageal landmarks. Special attention was also paid to the combined presence of squamous overgrowth, multilayered epithelium, hybrid glands and/or submucosal glands/ducts to differentiate intestinal metaplasia of the esophagus (ie, Barrett esophagus) from that of the cardia in both resection specimens and preoperative mucosal biopsies available for review. ${ }^{20}$ The histomorphology of tumors was classified as adenosquamous carcinoma, low-grade conventional adenocarcinoma (tubular, papillary and/or cribriform pattern, pG 1-2), poorly differentiated conventional adenocarcinoma (solid and/or nested patterns, pG 3), medullary carcinoma (solid growth with tumor infiltrating lymphocytes), mucinous carcinoma or signet ring cell carcinoma (Figure 1). In cases exhibiting a heterogeneous morphology, the most prevalent features of the highest grade were used in statistical analyses.

Tissue microarrays were constructed of 137 cases in which tissue blocks were available. For each case, 2-5 areas that represented each histomorphological subtype were evaluated on six 2-mm-core tissue microarrays, which also included normal gastric body/fundic mucosa, cardiac-type mucosa and Barrett mucosa as controls, as well as five cores of non-esophagogastric junction cancers on each.

\section{Immunohistochemical Analyses}

Immunohistochemical staining was performed on the tissue microarray sections, using a panel of markers previously reported to be indicators of intestinal (CDX2, CD10, MUC2) ${ }^{21-23}$ or gastric (MUC5AC, MUC6) ${ }^{23-26}$ phenotype. Nuclear $\beta$-catenin and MUC1 expression-previously reported to be prognostic biomarkers for adenocarcinomas of the stomach and esophagus ${ }^{27-29}$-was also evaluated. A Ventana autostainer (Benchmark XT) was used, following the manufacturer's instructions, with appropriate dilutions of antibodies to CDX2 (CDX2-88; Biogenex), CD10 (56C6; Ventana), MUC5AC (NCL-MUC5AC; Leica), MUC6 (NCLMUC6; Leica), MUC2 (NCL-MUC2; Leica), MUC1 
(NCL-MUC1; Leica) and $\beta$-catenin (14; Ventana). Sections were counterstained with hematoxylin.

Expression of each protein was considered to be positive when more than $10 \%$ of tumor cells in a section exhibited staining in the following cellular structures: CDX2, in the nucleus; CD10, on the cytoplasmic membrane; MUC2, MUC5AC and MUC6, in the cytoplasm; MUC 1, in the cytoplasm and/or on the membrane; and $\beta$-catenin, in the nucleus (Figure 1). Protein expression was collectively evaluated in all the tumor cells seen in multiple cores from each case.

Immunophenotype was classified as: intestinal if tumors stained positively for any of CDX2, CD10 and/or MUC2, and negatively for both MUC5AC and MUC6; gastric if positive for MUC5AC and/or MUC 6, and negative for CDX2, CD10 and MUC2; and mixed if positive for any combination of both intestinal and gastric markers, or null if all the cores from a case were negative for all five markers (Figures 2 and 3). ${ }^{25,30,31}$

\section{Molecular Analyses}

The overexpression of the epidermal growth factor receptors $E G F R$ and $E R B B 2$ has also been reported in association with unfavorable outcomes in esophageal adenocarcinomas. ${ }^{32-36}$ Thus, we conducted FISH for amplification of EGFR and ERBB2 on tissue microarray sections and/or conventional tissue sections. EGFR or ERBB2 gene copy number was considered to be amplified in the presence of a gene/chromosome ratio $\geq 2$ or homogeneously staining regions with $\geq 15$ copies in $\geq 10 \%$ of cells. ${ }^{37}$

\section{Statistics}

Data are shown as prevalence $(\%)$ or mean ( \pm standard deviation). We used the SAS program (Version 9.1, SAS Institute, Cary, NC, USA). All P-values were two-sided. When multiple hypothesis testing was performed, a $P$-value significance was adjusted by Bonferroni correction to $P=0.0050$. Continuous data were compared using the $t$-test, whereas categorical data was analyzed by the $\chi^{2}$-test or Fisher's exact test. Univariate analysis was performed to identify factors that were different in tumor subtypes. Overall survival was assessed by the Kaplan-Meier method, with prognostic factors evaluated by log-rank test. To assess independent effect of Barrett esophagus background on mortality, we constructed a multivariate, stage-matched (stratified using AJCC stage (I, II, III + IV)) Cox proportional hazard model to compute a hazard ratio (HR) according to Barrett esophagus background. A backward stepwise elimination with a threshold of $P=0.10$ was used to select variables in the final model. Variables in the final model were Barrett esophagus background, sex, age, surgical approaches, anemia, surveillance, tumor size, perineural invasion, surgical margin status, Muc1 expression and $\beta$-catenin nuclear expression.

\section{Results}

\section{Clinical Profile}

The study population consisted of 157 patients (29 women and 128 men) with surgically resected adenocarcinomas of the esophagogastric area. There were 153 Caucasians and 4 Asians. Patient age ranged from 36 to 94 years (median 65 years). There were 51 cases of Siewert type 1 adenocarcinoma and 106 Siewert type 2 (Table 1). An Ivor-Lewis procedure was performed in 70 patients, whereas a thoraco-abdominal approach was taken in 66 and transhiatal approach in 21 cases. Barrett esophagus was diagnosed preoperatively in 83 patients and was found in the resected esophagus of an additional 25 .

\section{Histopathological Characteristics}

Tumor size ranged from 0.1 to $11.5 \mathrm{~cm}$ (average: $3.8 \mathrm{~cm})$, and was greater than $3 \mathrm{~cm}$ in $98(62 \%)$ cases. Of 157 tumors, $79(50 \%)$ presented at an advanced stage (T3+ T4), $83(53 \%)$ were found to have nodal disease and $5(3 \%)$ had distant metastasis. Lymphovascular, venous and perineural invasion was present in 85 (54\%), 36 (23\%) and 67 (43\%) cases, respectively, and the resection margins (usually adventitial margin) were involved in 23 (15\%). Approximately half of the tumors (77, 49\%) were pure low-grade conventional adenocarcinoma, whereas most of the remaining cases $(71,45 \%)$ exhibited high-grade histology (pG3). By immunohistochemistry, over half of the cases $(71,52 \%)$ exhibited an intestinal or mixed phenotype; of these, 59 also showed CDX2 nuclear expression. As for biomarkers, MUC1 expression, nuclear $\beta$-catenin and EGFR amplification were noted in $83(60 \%), 52(38 \%)$ and $14(9 \%)$ cases, respectively.

\section{Clinicopathological Characteristics of Adenocarcinomas Stratified by the Background Mucosa}

Over two-thirds of the cases in this study presented with Barrett esophagus (intestinal-type mucosaassociated adenocarcinoma) (Table 2). However, only one-third of the patients with Barrett esophagus had been enrolled in surveillance endoscopy before presenting with invasive carcinoma. Patients with Barrett esophagus were more likely to be under the age of 65 years $(P=0.0057)$, and have more proximally located tumors $(P=0.0009)$, with a history of reflux symptoms $(P<0.0001)$, but no dysphagia $(P=0.011)$. In general, intestinal-type mucosa-associated adenocarcinomas were asso- 
ciated with better prognostic factors, including less advanced stage $(P<0.0001)$, absence of nodal metastases $(P=0.0001)$, negative resection margins $(P=0.0046), \quad$ lower-grade histology (pG 1-2, $P=0.0095)$ and no lymphatic $(P<0.0001)$, venous $(P=0.0060)$ or perineural invasion $(P<0.0001)$.
Histologically, intestinal-type mucosa-associated adenocarcinomas were more likely to show a glandular morphology $(P=0.0062)$, and exhibit an intestinal or mixed immunophenotype $(P=0.015)$, with more frequent CDX2 expression $(P=0.020)$. In terms of biomarker expression, intestinal-type
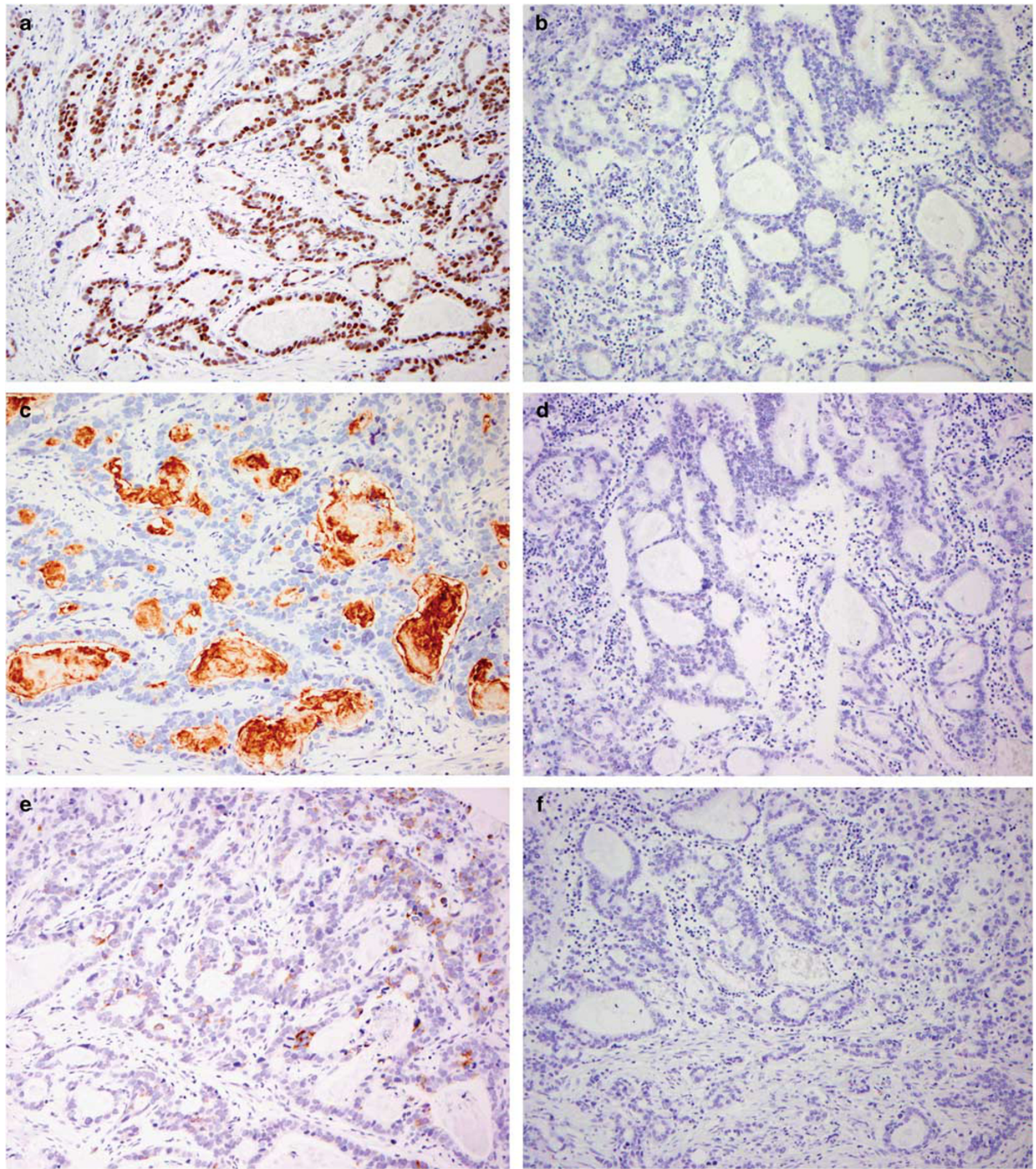

Figure 2 Intestinal (a, $\mathbf{c}, \mathbf{e}, \mathbf{g}, \mathbf{i})$ and gastric $(\mathbf{b}, \mathbf{d}, \mathbf{f}, \mathbf{h}, \mathbf{j})$ immunophenotypes. An example of the intestinal type shows nuclear expression of CDX2 (a), membranous staining of CD10 (c) and cytoplasmic expression of MUC2 in $>10 \%$ of the tumor cells (e). Conversely, MUC5AC (g) and MUC6 (i) are negative in the tumor cells. An example of the gastric type shows staining of MUC5AC (h) and MUC6 (j) in the majority of the tumor cells, but they are not reactive to CDX2 (b), CD10 (d) or MUC2 (f). 

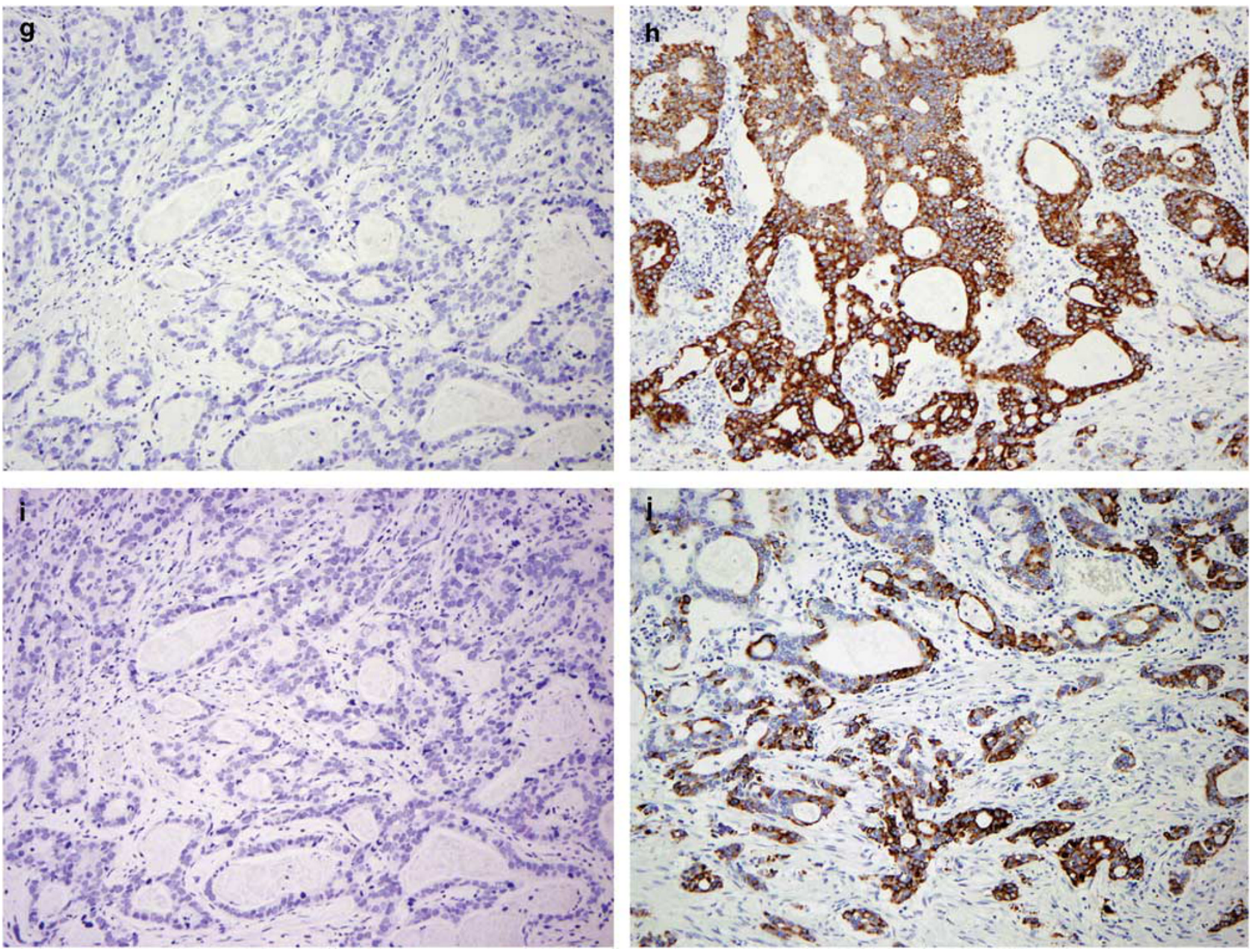

Figure 2 Continued.

mucosa-associated adenocarcinomas were more likely to have nuclear $\beta$-catenin staining $(P=0.0080)$, and less likely to exhibit EGFR amplification $(P=0.0051)$. Even when tumors greater than $3 \mathrm{~cm}$ alone were compared between the two groups, the differences in immunophenotypes and biomarker expression were preserved (Table 3).

\section{Clinicopathological Characteristics of Intestinal-Type Mucosa-Associated Adenocarcinomas by Surveillance History}

To account for the effects of endoscopic surveillance on stage and outcome, , $^{17,38}$ we compared the clinicopathological characteristics and survival between intestinal-type mucosa-associated adenocarcinomas found during surveillance and outside surveillance (Table 4). In our intestinal-type mucosa-associated adenocarcinoma cohort, there were 30 surveillance cases and 78 cases diagnosed with a symptomatic carcinoma. Those with an invasive carcinoma found during surveillance were more likely to have reflux symptoms $(P=0.0071)$, and were less likely to be anemic $(P=0.0093)$.
Furthermore, surveillance cases were less likely to have tumors greater than $1 \mathrm{~cm} \quad(P=0.0001)$, advanced T stage $(\mathrm{T} 3+\mathrm{T} 4, \quad P=0.021)$ or $\mathrm{MUC1}$ expression $(P=0.013)$.

No significant differences among intestinal-type mucosa-associated adenocarcinomas existed between surveillance and symptomatic tumor groups in histomorphology, immunophenotype or nuclear expression of $\beta$-catenin. More importantly, there were no differences in common prognostic factors such as lymph node metastasis, lymphovascular invasion or margin status between the two groups.

\section{Survival}

Five-year overall survival rate for patients with intestinal-type mucosa-associated adenocarcinoma was $28 \%$ and that for cardiac-type mucosa-associated adenocarcinoma was 9\% (log-rank $P=0.0015)$. When patients with intestinal-type mucosa-associated adenocarcinoma were stratified based on a history of surveillance for Barrett esophagus, patients on surveillance experienced an overall survival similar to patients without 
surveillance (log-rank $P=0.82$ ). Even stage by stage comparison did not reveal difference in overall survival between the two groups, although the low patient number in each category may have hampered statistical analysis.

\section{Predictors of Survival}

Using the Cox regression model, patients with intestinal-type mucosa-associated adenocarcinoma had a significant reduction in unadjusted overall
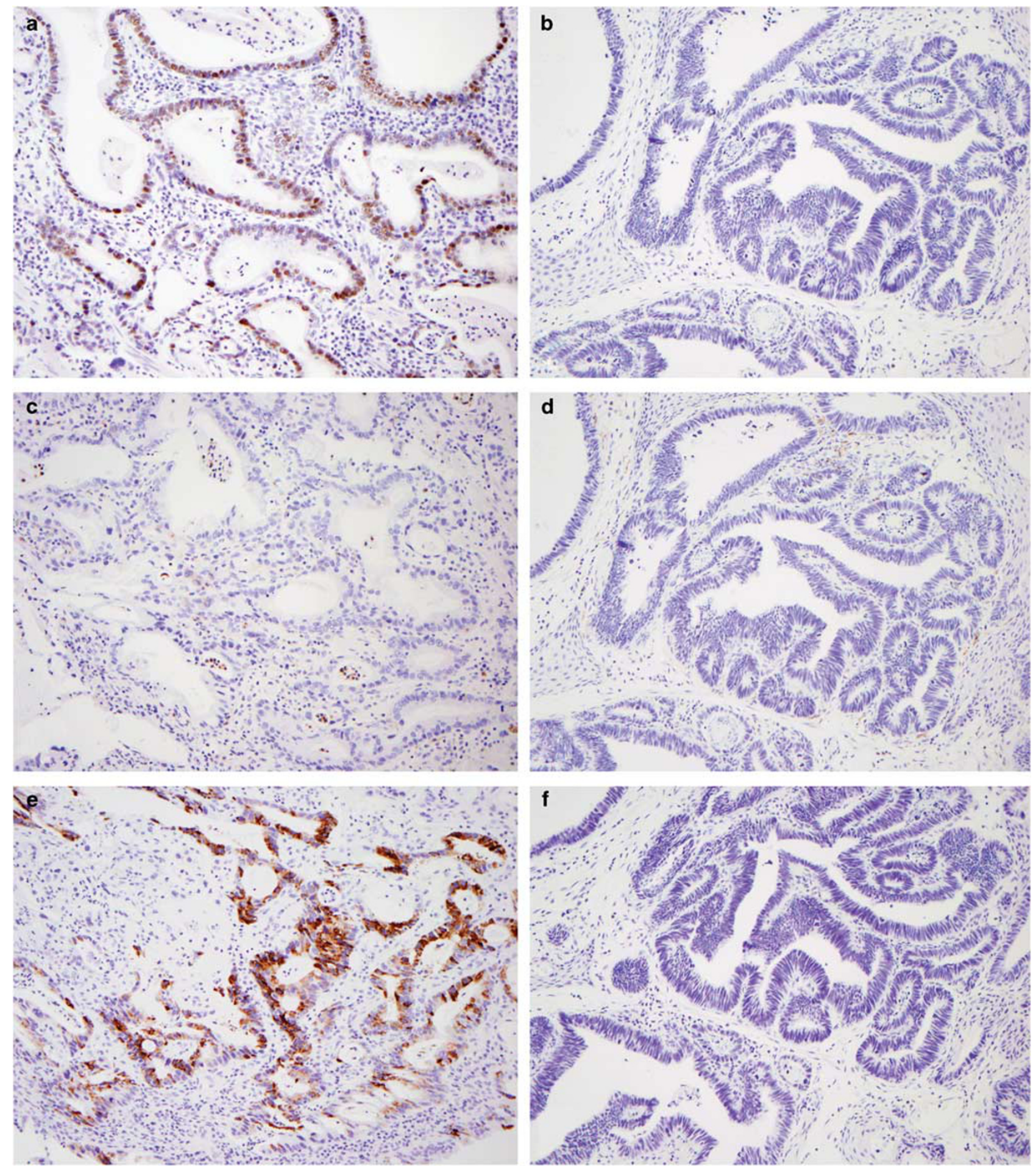

Figure 3 Mixed intestinal and gastric (a, $\mathbf{c}, \mathbf{e}, \mathbf{g}, \mathbf{i})$ and null $(\mathbf{b}, \mathbf{d}, \mathbf{f}, \mathbf{h}, \mathbf{j})$ immunophenotypes. An example of the mixed intestinal and gastric type exhibits concurrent expression of two intestinal markers (CDX2 (a) and MUC2 (e)) and gastric markers (MUC5AC (g) and MUC6 (i)). This example is negative for CD10 (c). The null type is characterized by negative expression of all five markers: CDX2 (b), CD10 (d), MUC2 (f), MUC5AC (h), and MUC6 (j). 

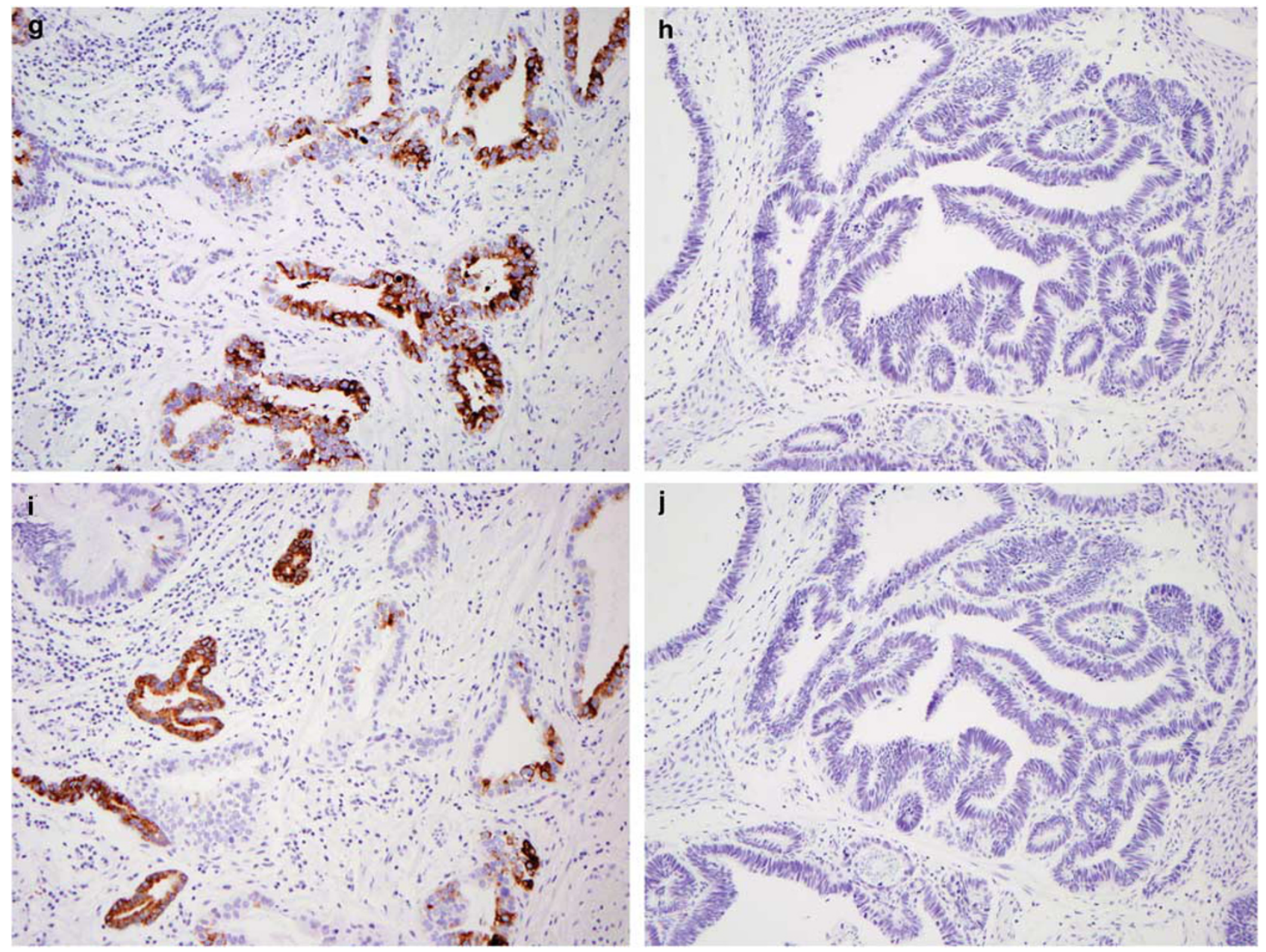

Figure 3 Continued.

Table 1 Clinicopathological characteristics by Siewert types

\begin{tabular}{|c|c|c|}
\hline & $\begin{array}{l}\text { Type } 1 \\
(\mathrm{n}=51)\end{array}$ & $\begin{array}{c}\text { Type } 2 \\
(\mathrm{n}=106)\end{array}$ \\
\hline Age at presentation (mean \pm s.d.) & $66 \pm 11$ & $65 \pm 11$ \\
\hline Male:female ratio* & $46: 5$ & $82: 24$ \\
\hline $\begin{array}{l}\text { Prevalence of intestinal } \\
\text { metaplasia }(\%)^{* *}\end{array}$ & 86 & 60 \\
\hline Histology (A/G/P/Med/M/S) ${ }^{a}$ & $1 / 23 / 11 / 2 / 4 / 10$ & $3 / 54 / 26 / 3 / 3 / 17$ \\
\hline $\begin{array}{l}\text { Immunophenotype } \\
(\mathrm{I} / \mathrm{G} / \mathrm{M} / \mathrm{N})^{\mathrm{b}, \mathrm{c}, * * *}\end{array}$ & $16 / 11 / 18 / 2$ & $22 / 30 / 19 / 19$ \\
\hline $\operatorname{CDX} 2(\%)^{\mathrm{b}}$ & 53 & 38 \\
\hline
\end{tabular}

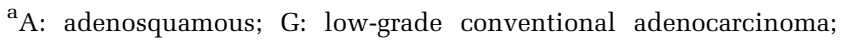
P: high-grade conventional adenocarcinoma; Med: medullary carcinoma; M: mucinous carcinoma; S: signet ring cell carcinoma.

${ }^{b}$ Immunostains were evaluated in 47 Siewert type 1 and 90 Siewert type 2 cases.

${ }^{\mathrm{C}} \mathrm{I}$ : intestinal; G: gastric; M: mixed; N: null immunophenotype.

${ }^{*} P=0.052 ;{ }^{*} P=0.0009 ;{ }^{*}{ }^{*} P=0.0037$.

mortality compared with those with cardiac-type mucosa-associated adenocarcinoma (HR: 0.48; $95 \%$ CI: 0.30-0.76). However, after stratification by AJCC tumor stage and adjustment for all the potential confounders, intestinal-type mucosa-associated adenocarcinomas showed no overall survival benefit (HR: 1.03 ; 95\% CI: $0.62-1.71$ and HR: $1.34 ; 95 \%$ CI 0.72-2.50, respectively). In this stage-matched Cox proportional hazard model, predictors of poor outcome included older age, the application of thoracoabdominal or transhiatal approach, perineural invasion, tumor size $>3 \mathrm{~cm}$ and MUC1 expression, whereas female gender, $1 \mathrm{~cm}$ or greater surgical clearance, and nuclear expression of $\beta$-catenin predicted a favorable outcome (Table 5). Similarly, upon multivariate analysis, there was no difference in overall mortality between patients with intestinal-type mucosa-associated adenocarcinoma and a history of surveillance vs those with intestinal-type mucosa-associated adenocarcinoma and no surveillance.

\section{Discussion}

Significant differences were found in mucin phenotype and molecular alterations between adenocarci- 
Table 2 Clinical and tumor characteristics by the presence of adjacent intestinal metaplasia

\begin{tabular}{|c|c|c|c|}
\hline & $\begin{array}{c}\text { Intestinal } \\
\text { metaplasia } \\
\text { present } \\
(\mathrm{n}=108)\end{array}$ & $\begin{array}{l}\text { Intestinal } \\
\text { metaplasia } \\
\text { absent } \\
(\mathrm{n}=49)\end{array}$ & $\mathrm{P}$-value \\
\hline Age (mean \pm s.d.) & $64 \pm 11.1$ & $67.3 \pm 10.4$ & 0.0057 \\
\hline Male:female ratio & $91: 17$ & $37: 12$ & 0.19 \\
\hline $\begin{array}{l}\text { History of } \\
\text { surveillance (\%) }\end{array}$ & 28 & 0 & $<0.0001$ \\
\hline Reflux (\%) & 67 & 28 & $<0.0001$ \\
\hline Anemia (\%) & 40 & 33 & 0.39 \\
\hline GI bleed (\%) & 16 & 16 & 1.00 \\
\hline Dysphagia (\%) & 51 & 74 & 0.011 \\
\hline $\begin{array}{l}\text { Location of tumor } \\
\text { (Siewert type } 1 \mathrm{vs} \\
\text { type 2) }\end{array}$ & $44 / 64$ & $7 / 42$ & 0.0009 \\
\hline $\begin{array}{l}\text { Surgical procedures } \\
(\mathrm{IL} / \mathrm{TA} / \mathrm{TH})^{\mathrm{a}}\end{array}$ & $54 / 34 / 20$ & $16 / 32 / 1$ & $0.043^{\mathrm{b}}$ \\
\hline Size (cm, mean \pm s.d.) & $3.4 \pm 2.0$ & $4.9 \pm 2.2$ & $<0.0001$ \\
\hline Tumors > $1 \mathrm{~cm} \mathrm{( \% )}$ & 86 & 100 & 0.0051 \\
\hline Tumors $>3 \mathrm{~cm} \mathrm{( \% )}$ & 54 & 86 & 0.0001 \\
\hline pT stage $(1 / 2 / 3 / 4)$ & $56 / 16 / 36 / 0$ & $2 / 4 / 42 / 1$ & $<0.0001^{\mathrm{c}}$ \\
\hline pN new AJCC $(0 / 1 / 2 / 3)$ & $64 / 20 / 12 / 10$ & $8 / 9 / 18 / 14$ & $0.0001^{\mathrm{d}}$ \\
\hline pM (Mx/M1) & $105 / 3$ & $47 / 2$ & 0.50 \\
\hline Lymphovascular invasion (\%) & 46 & 82 & $<0.0001$ \\
\hline Venous invasion (\%) & 19 & 41 & 0.0060 \\
\hline Perineural invasion (\%) & 34 & 73 & $<0.0001$ \\
\hline Resection margin $<1 \mathrm{~cm} \mathrm{( \% )}$ & 69 & 92 & 0.0022 \\
\hline Resection margin positive (\%) & 9 & 27 & 0.0046 \\
\hline pG grade $(1 / 2 / 3)$ & $21 / 45 / 41$ & $2 / 17 / 30$ & $0.0095^{\mathrm{e}}$ \\
\hline Histology (A/G/P/ & $2 / 61 / 22 /$ & $2 / 16 / 15 /$ & $0.0062^{\mathrm{g}}$ \\
\hline $\operatorname{Med} / \mathrm{M} / \mathrm{S})^{\mathrm{f}}$ & $3 / 5 / 15$ & $2 / 2 / 12$ & \\
\hline $\begin{array}{l}\text { Immunophenotype } \\
(\mathrm{I} / \mathrm{G} / \mathrm{M} / \mathrm{N})^{\mathrm{h}, \mathrm{i}}\end{array}$ & $26 / 25 / 31 / 10$ & $12 / 16 / 6 / 11$ & $0.015^{\mathrm{j}}$ \\
\hline $\operatorname{CDX} 2(\%)^{\mathrm{i}}$ & 49 & 28 & 0.020 \\
\hline $\operatorname{MUC1}(\%)^{\mathrm{i}}$ & 61 & 57 & 0.59 \\
\hline$\beta$-Catenin $(\%)^{\mathrm{i}}$ & 46 & 22 & 0.0080 \\
\hline FISH $(E G F R / E R B B 2 / \mathrm{no}$ & $5 / 9 / 94$ & $9 / 2 / 38$ & $0.0051^{\mathrm{k}}$ \\
\hline
\end{tabular}

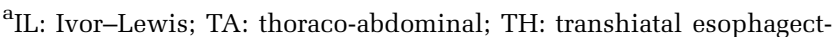
omy or esophagogastrectomy.

${ }^{\mathrm{b}} \mathrm{IL}$ vs TA+TH.

${ }^{\mathrm{c}} \mathrm{T} 1-2$ vs $\mathrm{T} 3-4$.

$\mathrm{d}$ pNo vs pN1-3.

epG1-2 vs pG3.

${ }^{\mathrm{f}} \mathrm{A}$ : adenosquamous; G: low-grade conventional adenocarcinoma; P: high-grade conventional adenocarcinoma; Med: medullary carcinoma; M: mucinous carcinoma; S: signet ring cell carcinoma.

${ }^{\mathrm{g}} \mathrm{G}$ vs the others.

${ }^{\mathrm{h}}$ I: intestinal; G: gastric; M: mixed; N: null immunophenotype.

${ }^{\mathrm{i}}$ Immunostains were evaluated in 92 with and 45 without intestinal metaplasia cases.

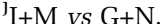

${ }^{\mathrm{k}}$ EGFR positive vs EGFR negative.

nomas arising in association with Barrett mucosa and those that do not. Intestinal-type mucosaassociated adenocarcinomas were more likely to exhibit an intestinal or mixed intestinal/gastric immunophenotype, and express nuclear $\beta$-catenin. In contrast, cardiac-type mucosa-associated adenocarcinomas were more likely to correlate with EGFR amplification. These findings support the notion that two different pathways lead to adenocarcinomas of the distal esophagus and esophagogastric junction: one in which intestinal-type epithelium with goblet
Table 3 Clinical and tumor characteristics of large tumors $(>3 \mathrm{~cm})$

\begin{tabular}{|c|c|c|c|}
\hline & $\begin{array}{l}\text { Intestinal } \\
\text { metaplasia } \\
\text { present } \\
(\mathrm{n}=56)\end{array}$ & $\begin{array}{l}\text { Intestinal } \\
\text { metaplasia } \\
\text { absent } \\
(\mathrm{n}=42)\end{array}$ & P-value \\
\hline Age (mean \pm s.d.) & $66.4 \pm 10.7$ & $66.2 \pm 10.7$ & 0.91 \\
\hline Male:female ratio & $50: 6$ & $30: 12$ & 0.034 \\
\hline History of surveillance (\%) & 16 & 0 & 0.0091 \\
\hline Reflux (\%) & 37 & 0 & $<0.0001$ \\
\hline Anemia (\%) & 50 & 31 & 0.066 \\
\hline GI bleed (\%) & 16 & 18 & 0.78 \\
\hline Dysphagia (\%) & 59 & 75 & 0.17 \\
\hline $\begin{array}{l}\text { Location of tumor } \\
\text { (Siewert type } 1 \text { vs type } 2 \text { ) }\end{array}$ & $26 / 30$ & $6 / 36$ & 0.0010 \\
\hline $\begin{array}{l}\text { Surgical procedures } \\
\text { (IL/TA/TH) }^{\mathrm{a}}\end{array}$ & $27 / 17 / 12$ & $15 / 26 / 1$ & $0.30^{\mathrm{b}}$ \\
\hline Size $(\mathrm{cm}$, mean \pm s.d. $)$ & $4.9 \pm 1.5$ & $5.3 \pm 2.1$ & 0.24 \\
\hline pT stage $(1 / 2 / 3 / 4)$ & $14 / 12 / 30 / 0$ & $2 / 2 / 37 / 1$ & $0.0001^{\mathrm{c}}$ \\
\hline pN new AJCC $(0 / 1 / 2 / 3)$ & $26 / 12 / 8 / 10$ & 7/6/17/12 & $0.0024^{\mathrm{d}}$ \\
\hline $\mathrm{PM}(\mathrm{Mx} / \mathrm{M} 1)$ & $53 / 3$ & $40 / 2$ & 1.00 \\
\hline Lymphovascular invasion (\%) & 59 & 83 & 0.013 \\
\hline Venous invasion (\%) & 29 & 40 & 0.37 \\
\hline Perineural invasion (\%) & 45 & 76 & 0.0035 \\
\hline Resection margin $<1 \mathrm{~cm} \mathrm{( \% )}$ & 84 & 93 & 0.23 \\
\hline Resection margin positive (\%) & 16 & 29 & 0.15 \\
\hline pG grade $(1 / 2 / 3)$ & $2 / 25 / 29$ & $0 / 16 / 26$ & $0.41^{\mathrm{e}}$ \\
\hline Histology $(\mathrm{A} / \mathrm{G} / \mathrm{P} / \mathrm{Med} / \mathrm{M} / \mathrm{S})^{\mathrm{f}}$ & $\begin{array}{c}1 / 23 / 15 / \\
3 / 5 / 9\end{array}$ & $\begin{array}{l}2 / 14 / 11 / \\
2 / 7 / 6\end{array}$ & $0.53^{\mathrm{g}}$ \\
\hline $\begin{array}{l}\text { Immunophenotype } \\
(\mathrm{I} / \mathrm{G} / \mathrm{M} / \mathrm{N})^{\mathrm{h}, \mathrm{i}}\end{array}$ & $16 / 12 / 18 / 6$ & $12 / 13 / 5 / 9$ & $0.038^{\mathrm{j}}$ \\
\hline CDX2 (\%) $)^{i}$ & 54 & 30 & 0.033 \\
\hline MUC1 $(\%)^{\mathrm{i}}$ & 71 & 55 & 0.13 \\
\hline$\beta$-Catenin $(\%)^{\mathrm{i}}$ & 52 & 23 & 0.0089 \\
\hline FISH (EGFR/ERBB2/no amp) & $2 / 5 / 49$ & $7 / 2 / 33$ & $0.033^{\mathrm{k}}$ \\
\hline \multirow{2}{*}{\multicolumn{4}{|c|}{$\begin{array}{l}\text { a IL: Ivor-Lewis; TA: thoraco-abdominal; TH: transhiatal esophagect- } \\
\text { omy or esophagogastrectomy. } \\
\text { bIL vs TA+TH. }\end{array}$}} \\
\hline & & & \\
\hline \multicolumn{4}{|l|}{${ }^{\mathrm{C}} \mathrm{T} 1-2$ vs $\mathrm{T} 3-4}$. \\
\hline \multicolumn{4}{|l|}{${ }^{\mathrm{d}} \mathrm{pN} 0$ vs pN1-3. } \\
\hline \multicolumn{4}{|l|}{${ }^{\mathrm{e}} \mathrm{pG} 1-2$ vs pG3. } \\
\hline \multirow{2}{*}{\multicolumn{4}{|c|}{ 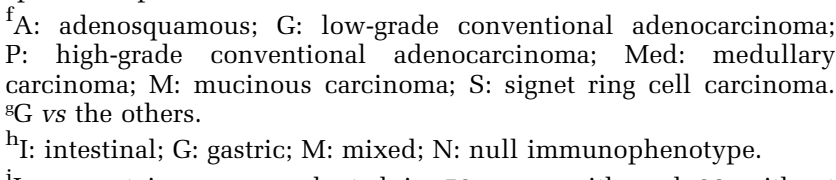 }} \\
\hline & & & \\
\hline \multirow{2}{*}{\multicolumn{4}{|c|}{$\begin{array}{l}{ }^{\mathrm{i}} \text { Immunostains were evaluated in } 52 \text { cases with and } 39 \text { without } \\
\text { intestinal metaplasia. } \\
\mathrm{j}_{\mathrm{I}+\mathrm{M} \text { vs G+N. }}\end{array}$}} \\
\hline & & & \\
\hline $\mathrm{k}_{E G F B}$ nositive vs $F G \mathrm{l}$ & & & \\
\hline
\end{tabular}

cells becomes dysplastic (intestinal pathway) and another in which dysplasia arises in cardiac-type glandular mucosa (non-intestinal pathway). ${ }^{39-41}$ In contrast, an alternative explanation for the lack of intestinal metaplasia in some adenocarcinomas, ${ }^{39}$ overgrowth of short segment intestinal metaplasia by large tumors, ${ }^{17,42}$ explains neither the absence of intestinal-type mucosa in certain small esophageal adenocarcinomas ${ }^{43}$ nor our observation of phenotypic and molecular differences. Thus, adenocarcinomas of the distal esophagus and esophagogastric junction may be stratified based on the presence or absence of background Barrett mucosa, with unique clinicopathological characteristics in either group, but without significant survival differences. 
Table 4 Clinical and tumor characteristics of intestinal-type mucosa-associated adenocarcinoma stratified by history of surveillance

\begin{tabular}{|c|c|c|c|}
\hline & $\begin{array}{c}\text { No } \\
\text { surveillance } \\
(\mathrm{n}=78)\end{array}$ & $\begin{array}{l}\text { Surveillance } \\
\quad(\mathrm{n}=30)\end{array}$ & $\mathrm{P}$-value \\
\hline Age (mean \pm s.d.) & $65.9 \pm 11.2$ & $60.6 \pm 9.9$ & 0.025 \\
\hline Male:female ratio & $65: 13$ & $26: 4$ & 0.77 \\
\hline Reflux (\%) & 59 & 89 & 0.0071 \\
\hline Anemia (\%) & 47 & 20 & 0.0093 \\
\hline GI bleed (\%) & 20 & 4 & 0.10 \\
\hline Dysphagia (\%) & 53 & 44 & 0.45 \\
\hline $\begin{array}{l}\text { Location of tumor (Siewert } \\
\text { type } 1 \text { vs type } 2 \text { ) }\end{array}$ & $33 / 45$ & $11 / 19$ & 0.67 \\
\hline $\begin{array}{l}\text { Surgical procedures } \\
\text { (IL/TA/TH) }^{\mathrm{a}}\end{array}$ & $38 / 26 / 14$ & $16 / 8 / 6$ & $0.80^{\mathrm{b}}$ \\
\hline Size (cm, mean \pm s.d.) & $3.9 \pm 2.0$ & $2.0 \pm 1.3$ & $<0.0001$ \\
\hline Tumors > $1 \mathrm{~cm} \mathrm{( \% )}$ & 95 & 63 & 0.0001 \\
\hline Tumors > $3 \mathrm{~cm}(\%)$ & 64 & 30 & 0.0024 \\
\hline pT stage $(1 / 2 / 3 / 4)$ & $35 / 11 / 32 / 0$ & $21 / 5 / 4 / 0$ & $0.021^{\mathrm{c}}$ \\
\hline pN new AJCC $(0 / 1 / 2 / 3)$ & $42 / 15 / 9 / 10$ & $22 / 5 / 3 / 0$ & $0.14^{\mathrm{d}}$ \\
\hline $\mathrm{pM}(\mathrm{Mx} / \mathrm{M} 1)$ & $75 / 3$ & $30 / 0$ & 0.56 \\
\hline $\begin{array}{l}\text { Lymphovascular } \\
\text { invasion }(\%)\end{array}$ & 50 & 35 & 0.18 \\
\hline Venous invasion (\%) & 23 & 8 & 0.14 \\
\hline Perineural invasion (\%) & 37 & 26 & 0.33 \\
\hline Resection margin $<1 \mathrm{~cm}(\%)$ & 74 & 57 & 0.10 \\
\hline Resection margin positive (\%) & 10 & 7 & 0.72 \\
\hline pG grade $(1 / 2 / 3)$ & $10 / 38 / 30$ & $12 / 7 / 11$ & $1.00^{\mathrm{e}}$ \\
\hline Histology $(\mathrm{A} / \mathrm{G} / \mathrm{P} / \mathrm{Med} / \mathrm{M} / \mathrm{S})^{\mathrm{f}}$ & $2 / 43 / 13 / 3 / 4 / 13$ & $0 / 18 / 9 / 0 / 1 / 2$ & $0.67^{\mathrm{g}}$ \\
\hline $\begin{array}{l}\text { Immunophenotype } \\
(\mathrm{I} / \mathrm{G} / \mathrm{M} / \mathrm{N})^{\mathrm{h}, \mathrm{i}}\end{array}$ & $20 / 20 / 25 / 7$ & $6 / 5 / 6 / 3$ & $0.84^{\mathrm{j}}$ \\
\hline $\operatorname{CDX} 2(\%)^{\mathrm{i}}$ & 49 & 48 & 0.89 \\
\hline $\operatorname{MUC1}(\%)^{\mathrm{i}}$ & 68 & 38 & 0.013 \\
\hline$\beta$-Catenin $(\%)^{\mathrm{i}}$ & 48 & 37 & 0.39 \\
\hline FISH (EGFR/ERBB2/no amp) & $3 / 7 / 68$ & $2 / 2 / 26$ & $0.62^{\mathrm{k}}$ \\
\hline
\end{tabular}

${ }^{\mathrm{a}}$ IL: Ivor-Lewis; TA: thoraco-abdominal; TH: transhiatal esophagectomy or esophagogastrectomy.

${ }^{\mathrm{b}} \mathrm{IL}$ vs $\mathrm{TA}+\mathrm{TH}$.

${ }^{\mathrm{C}} \mathrm{T} 1-2$ vs $\mathrm{T} 3-4$.

d $\mathrm{pN} 0$ vs pN1-3.

e pG1-2 vs 3 .

${ }^{\mathrm{f}} \mathrm{A}$ : adenosquamous; G: low-grade conventional adenocarcinoma; P: high-grade conventional adenocarcinoma; Med: medullary carcinoma; M: mucinous carcinoma; S: signet ring cell carcinoma.

${ }^{\mathrm{g}} \mathrm{G}$ vs the others.

${ }^{\mathrm{h}} \mathrm{I}$ : intestinal; G: gastric; $\mathrm{M}$ : mixed; N: null immunophenotype.

${ }^{\mathrm{i}}$ Immunostains were evaluated in 20 cases with and 72 without surveillance.

${ }^{\mathrm{j}} \mathrm{I}+\mathrm{M}$ vs $\mathrm{G}+\mathrm{N}$.

${ }^{\mathrm{k}}$ EGFR positive vs EGFR negative.

Table 5 Multivariate analysis of factors associated with survival after resection

\begin{tabular}{lccc}
\hline & P-value & HR & 95\% CI \\
\hline Age & $<0.0001$ & 1.07 & $1.04-1.10$ \\
Gender (female) & 0.037 & 0.40 & $0.17-0.95$ \\
Anemia & 0.018 & 1.85 & $1.04-3.28$ \\
Surgical procedure (TA or TH) & 0.035 & 2.14 & $1.13-4.06$ \\
Perineural invasion & 0.0004 & 3.88 & $1.83-8.21$ \\
Tumor size > 3 cm & 0.0084 & 2.75 & $1.30-5.82$ \\
Surgical clearance >1 cm & 0.037 & 0.39 & $0.16-0.94$ \\
$\beta$-Catenin (nuclear) & 0.026 & 0.48 & $0.25-0.92$ \\
MUC1 & 0.019 & 2.14 & $1.13-4.06$ \\
Barrett esophagus & 0.36 & & \\
Reflux symptom & 0.19 & & \\
\hline
\end{tabular}

The association of an intestinal or mixed immunophenotype (especially CDX2 expression) with intestinal-type mucosa-associated adenocarcinoma is in keeping with current understanding of the pathogenesis of intestinal metaplasia. Normally CDX2 is localized to the small and large bowel, ${ }^{44,45}$ where it is responsible for the maintenance of intestinal phenotype, ${ }^{21,22}$ including the upregulation of MUC2, an intestinal-type mucin, in goblet cells. ${ }^{31,46}$ CDX2 expression has also been reported in $54 \%$ of gastric carcinomas, often in conjunction with MUC2 expression. ${ }^{47}$ In this milieu, CDX2 is associated with tumor progression, during which tumors undergo an immunophenotypic shift from gastric phenotype (MUC5AC and/or MUC6 positive) to intestinal phenotype. ${ }^{30}$ Thus, intestinal-type differentiation can be seen in both pre- and postneoplastic transformation. Conversely, loss or decrease in CDX2 expression has been shown in Barrett esophagus-related dysplasia. ${ }^{48,49}$ This observation raises the possibility that the association of intestinal-type mucosa-associated adenocarcinoma with an intestinal or mixed phenotype merely reflects the fact that it presents at a lower tumor stage than cardiac-type mucosa-associated adenocarcinoma. However, in our population, the difference in the prevalence of the intestinal and mixed phenotype between intestinal- or cardiac-type mucosa-associated adenocarcinomas was preserved even in large tumors ( $>3 \mathrm{~cm}$ in diameter), and in more advanced stage tumors.

$\beta$-Catenin is normally expressed on the cell membrane in non-dysplastic esophageal squamous epithelium and Barrett esophagus. ${ }^{50}$ Abnormal expression (loss of membranous expression and focal nuclear staining) can be seen even in low-grade dysplasia and is prevalent in carcinoma. ${ }^{50-52}$ Thus, nuclear accumulation of $\beta$-catenin is considered to be a common and early event during neoplastic progression of Barrett esophagus. ${ }^{53}$ Abnormal $\beta$-catenin expression has also been reported in gastric adenocarcinoma, especially in association with intestinal phenotype, although it is usually seen in more advanced tumors. ${ }^{27}$ In our study, we found that abnormal nuclear $\beta$-catenin expression was more prevalent in intestinal-type mucosaassociated adenocarcinoma than in cardiac-type mucosa-associated adenocarcinoma, confirming that $\beta$-catenin misregulation may have a specific role in carcinogenesis of the intestinal-type mucosa. Nuclear expression of $\beta$-catenin was also associated with favorable outcomes in multivariate analysis. This is in keeping with a previous report that abnormal $\beta$-catenin expression was associated with better survival irrespective of depth of invasion in patients with intestinal-type mucosa-associated adenocarcinoma. ${ }^{29}$

Increased expression of EGFR and/or amplification of $7 \mathrm{p} 12$ (chromosomal locus of EGFR) have been reported in $30-60 \%$ of esophageal and esophagogastric junction adenocarcinomas. ${ }^{32,33,54}$ 
Interestingly, while elevated levels of EGFR have been identified in non-dysplastic intestinal metaplasia, ${ }^{55-57}$ we found EGFR amplification to be more highly associated with cardiac-type mucosa-associated adenocarcinoma. EGFR has also been linked to high-grade tumors and poor survival. ${ }^{32-34}$ Given these findings, EGFR amplification could be construed to be a later event in more advanced cancers. However, even when comparing only large tumors, EGFR amplification was significantly more frequent in cardiac-type mucosa-associated adenocarcinomas than in intestinal-type mucosa-associated adenocarcinomas. Taken together with the other immunophenotypic differences between intestinal- and cardiac-type mucosa-associated adenocarcinomas, this suggests that different pathways are involved in carcinogenesis of the two types of adenocarcinoma arising in the vicinity of the esophagogastric junction.

Growing evidence has also suggested the presence of a non-intestinal-type neoplastic pathway in the distal esophagus and esophagogastric junction. In one study of 300 patients older than 65 years, $36 \%$ showed endoscopic evidence of short segment Barrett esophagus. Of those, the majority (57\%) did not exhibit microscopic intestinal metaplasia. ${ }^{58}$ In another large cohort, $45 \%$ of those with endoscopically diagnosed Barrett esophagus had no microscopic evidence of intestinal metaplasia, yet 3.6\% ultimately developed adenocarcinoma. This was not statistically different from the $7.4 \%$ of patients with Barrett esophagus who developed adenocarcinoma. ${ }^{59}$ On the basis of these results, it is reasonable to speculate that metaplastic columnar epithelium without intestinal metaplasia (gastric/cardiac type metaplasia) in the distal esophagus and esophagogastric junction is not uncommon, especially in the older population, and could be a precursor to the non-intestinal-type adenocarcinoma. Therefore, our results, if confirmed, would support the recent recommendation of AGA that defines 'Barrett esophagus' as the condition in which any extent of metaplastic columnar epithelium (irrespective of the presence of goblet cells) that predisposes to cancer development replaces the native squamous epithelium of the distal esophagus, ${ }^{60}$ and could be the basis for challenging the current surveillance protocol.

Although our results revealed the difference in clinicopathological characteristics between intestinal- and cardiac-type mucosa-associated adenocarcinomas, we did not find a survival advantage by either group, after stratification by tumor stage. Instead, survival was affected by other well-known prognostic factors, including perineural invasion, tumor size, age and gender. ${ }^{61}$ Although stage for stage, the presence of intestinal metaplasia did not affect tumor prognosis, intestinal-type mucosa-associated adenocarcinoma often presented at an earlier stage. This could be attributed to either endoscopic surveillance or symptomatic gastroesophageal reflux, ${ }^{62}$ prompting an endoscopic workup with incidental identification of malignancy. The results of this study, however, raise the possibility of wellestablished intestinal milieu preventing tumor progression. In support of this hypothesis, it has been reported that CDX2 has a tumor suppressor function in the colon. ${ }^{63} \mathrm{Cdx} 2^{+/-}$mice developed adenocarcinomas after carcinogen treatment specifically in the distal colon, where the lowest expression of $C d x 2$ is found. ${ }^{63}$ Thus, lack or reduced CDX2 of cardiac-type epithelium compared with intestinal-type epithelium in the distal esophagus and esophagogastric junction $^{48}$ may facilitate tumor progression. This hypothesis, however, has yet to be confirmed in prospective studies.

Our study has several limitations that are inherent to a retrospective study using resected specimens. Most importantly, the absence of intestinal metaplasia in non-neoplastic columnar mucosa could be attributed incomplete sampling of the lesion, especially in large tumors that involved the esophagogastric junction circumferentially. Such tumors may have overgrown short segment Barrett esophagus as well. ${ }^{17,42}$ In our cohort, $24 \%(20 / 83)$ of the patients with a preoperative diagnosis of pathologically confirmed Barrett esophagus failed to reveal intestinal metaplasia of the esophagus in the examined sections (data not shown). To overcome this issue, we included such cases in the intestinaltype mucosa-associated adenocarcinoma group, and subsequently showed the difference in clinical characteristics, such as the presence of reflux symptoms, between intestinal- and cardiac-type mucosa-associated adenocarcinoma cases. Furthermore, the difference in clinicopathological characteristics between the two groups was preserved even when large tumors alone were compared. To accurately assess tumor immunophenotype and histomorphological characteristics, we excluded a large group of tumors with preoperative therapy. The exclusion of these cases resulted in a relatively small study size, and it is possible that the lack of statistical significance in some of our analyses is due to inadequate case numbers. A larger study might be helpful in this regard.

In summary, review of adenocarcinomas of the distal esophagus and esophagogastric junction at our institution found that tumors arising in association with Barrett esophagus had significantly different immunophenotypic and molecular characteristics from those arising in cardiac-type mucosa, supporting the theory that divergent pathways of metaplasia and dysplasia exist in esophagogastric tumorigenesis. Additional studies are warranted to further clarify their pathogenesis and the molecular mechanisms involved.

\section{Disclosure/conflict of interest}

The authors declare no conflict of interest. 
Author contributions: Study concept and design: Mari Mino-Kenudson; acquisition of data: Elizabeth G Demicco, Alton B Farris III, Brian Agbor-Etang, Kristin Bergethon, Rajini Mandal, Diane Davies, Junya Fukuoka, Michio Shiizu, Dora Dias-Santagata, and Mari Mino-Kenudson; analysis and interpretation: Elizabeth G Demicco, A John Iafrate, and Mari Mino-Kenudson; drafting of the manuscript: Elizabeth G Demicco, Henning A Gaissert, and Mari Mino-Kenudson; critical revision of the manuscript for important intellectual content: Elizabeth G Demicco, Alton B Farris III, Yoshifumi Baba, Brian Agbor-Etang, Kristin Bergethon, Rajini Mandal, Diane Davies, Junya Fukuoka, Michio Shiizu, Dora Dias-Santagata, Shuji Ogino, A John Iafrate, Hennig A Gaissert, and Mari Mino-Kenudson; statistical analysis: Yoshifumi Baba and Shuji Ogino; study supervision: Henning A Gaissert and Mari MinoKenudson.

\section{References}

1 DeMeester SR. Adenocarcinoma of the esophagus and cardia: a review of the disease and its treatment. Ann Surg Oncol 2006;13:12-30.

2 Jemal A, Siegel R, Ward E, et al. Cancer statistics, 2009. CA Cancer J Clin 2009;59:225-249.

3 Stein HJ, Feith M, Siewert JR. Cancer of the esophagogastric junction. Surg Oncol 2000;9:35-41.

4 Siewert JR, Stein HJ, Feith M. Adenocarcinoma of the esophago-gastric junction. Scand J Surg 2006;95:260269.

5 McColl KE, Going JJ. Aetiology and classification of adenocarcinoma of the gastro-oesophageal junction/ cardia. Gut 2010;59:282-284.

6 Whitson BA, Groth SS, Li Z, et al. Survival of patients with distal esophageal and gastric cardia tumors: a population-based analysis of gastroesophageal junction carcinomas. J Thorac Cardiovasc Surg 2010;139:43-48.

7 Ectors N, Driessen A, De Hertog G, et al. Is adenocarcinoma of the esophagogastric junction or cardia different from Barrett adenocarcinoma? Arch Pathol Lab Med 2005;129:183-185.

8 Edge SB, Byrd DR, Compton CC, et al (eds). AJCC Cancer Staging Manual. Springer: New York, 2009.

9 Hameeteman W, Tytgat GN, Houthoff HJ, et al. Barrett's esophagus: development of dysplasia and adenocarcinoma. Gastroenterology 1989;96:1249-1256.

10 Ruol A, Parenti A, Zaninotto G, et al. Intestinal metaplasia is the probable common precursor of adenocarcinoma in Barrett esophagus and adenocarcinoma of the gastric cardia. Cancer 2000;88:2520-2528.

11 Crew KD, Neugut AI. Epidemiology of upper gastrointestinal malignancies. Semin Oncol 2004;31: 450-464.

12 Lagergren J, Bergstrom R, Lindgren A, et al. Symptomatic gastroesophageal reflux as a risk factor for esophageal adenocarcinoma. N Engl J Med 1999;340:825-831.

13 Brown LM, Devesa SS, Chow WH. Incidence of adenocarcinoma of the esophagus among white Americans by sex, stage, and age. J Natl Cancer Inst 2008; 100:1184-1187.
14 Duhaylongsod FG, Wolfe WG. Barrett's esophagus and adenocarcinoma of the esophagus and gastroesophageal junction. J Thorac Cardiovasc Surg 1991;102: 36-41; discussion -2 .

15 Menke-Pluymers MB, Schoute NW, Mulder AH, et al. Outcome of surgical treatment of adenocarcinoma in Barrett's oesophagus. Gut 1992;33:1454-1458.

16 Sabel MS, Pastore K, Toon $\mathrm{H}$, et al. Adenocarcinoma of the esophagus with and without Barrett mucosa. Arch Surg 2000;135:831-835; discussion 6.

17 Portale G, Peters JH, Hagen JA, et al. Comparison of the clinical and histological characteristics and survival of distal esophageal-gastroesophageal junction adenocarcinoma in patients with and without Barrett mucosa. Arch Surg 2005;140:570-574; discussion 4-5.

18 Siewert JR, Stein HJ. Classification of adenocarcinoma of the oesophagogastric junction. Br J Surg 1998;85: 1457-1459.

19 Misumi A, Murakami A, Harada K, et al. Definition of carcinoma of the gastric cardia. Langenbecks Arch Chir 1989;374:221-226.

20 Srivastava A, Odze RD, Lauwers GY, et al. Morphologic features are useful in distinguishing Barrett esophagus from carditis with intestinal metaplasia. Am J Surg Pathol 2007;31:1733-1741.

21 Chawengsaksophak K, James R, Hammond VE, et al. Homeosis and intestinal tumours in Cdx2 mutant mice. Nature 1997;386:84-87.

22 Beck F, Chawengsaksophak K, Waring $\mathrm{P}$, et al. Reprogramming of intestinal differentiation and intercalary regeneration in Cdx2 mutant mice. Proc Natl Acad Sci USA 1999;96:7318-7323.

$23 \mathrm{Li} \mathrm{XL}$, Eishi Y, Bai YQ, et al. Expression of the SRY-related HMG box protein SOX2 in human gastric carcinoma. Int J Oncol 2004;24:257-263.

24 Pinto-de-Sousa J, David L, Reis CA, et al. Mucins MUC1, MUC2, MUC5AC and MUC6 expression in the evaluation of differentiation and clinico-biological behaviour of gastric carcinoma. Virchows Arch 2002; 440:304-310.

25 Reis CA, David L, Carvalho F, et al. Immunohistochemical study of the expression of MUC6 mucin and co-expression of other secreted mucins (MUC5AC and MUC2) in human gastric carcinomas. J Histochem Cytochem 2000;48:377-388.

26 Reis CA, David L, Correa P, et al. Intestinal metaplasia of human stomach displays distinct patterns of mucin (MUC1, MUC2, MUC5AC, and MUC6) expression. Cancer Res 1999;59:1003-1007.

27 Ogasawara N, Tsukamoto T, Mizoshita T, et al. Mutations and nuclear accumulation of beta-catenin correlate with intestinal phenotypic expression in human gastric cancer. Histopathology 2006;49:612-621.

28 Ohno T, Aihara R, Kamiyama Y, et al. Prognostic significance of combined expression of MUC1 and adhesion molecules in advanced gastric cancer. Eur J Cancer 2006;42:256-263.

29 Osterheld MC, Bian YS, Bosman FT, et al. Beta-catenin expression and its association with prognostic factors in adenocarcinoma developed in Barrett esophagus. Am J Clin Pathol 2002;117:451-456.

30 Tatematsu M, Tsukamoto T, Inada K. Stem cells and gastric cancer: role of gastric and intestinal mixed intestinal metaplasia. Cancer Sci 2003;94:135-141.

31 Yamamoto H, Bai YQ, Yuasa Y. Homeodomain protein CDX2 regulates goblet-specific MUC2 gene expression. Biochem Biophys Res Commun 2003;300:813-818. 
32 al-Kasspooles $\mathrm{M}$, Moore $\mathrm{JH}$, Orringer $\mathrm{MB}$, et al. Amplification and over-expression of the EGFR and erbB-2 genes in human esophageal adenocarcinomas. Int J Cancer 1993;54:213-219.

33 Yacoub L, Goldman H, Odze RD. Transforming growth factor-alpha, epidermal growth factor receptor, and $\mathrm{MiB}$ 1 expression in Barrett's-associated neoplasia: correlation with prognosis. Mod Pathol 1997;10:105-112.

34 Wilkinson NW, Black JD, Roukhadze E, et al. Epidermal growth factor receptor expression correlates with histologic grade in resected esophageal adenocarcinoma. J Gastrointest Surg 2004;8:448-453.

35 Brien TP, Odze RD, Sheehan CE, et al. HER-2/neu gene amplification by FISH predicts poor survival in Barrett's esophagus-associated adenocarcinoma. Hum Pathol 2000;31:35-39.

36 Nakamura $\mathrm{T}$, Nekarda $\mathrm{H}$, Hoelscher $\mathrm{AH}$, et al. Prognostic value of DNA ploidy and c-erbB-2 oncoprotein overexpression in adenocarcinoma of Barrett's esophagus. Cancer 1994;73:1785-1794.

37 Sholl LM, John Iafrate A, Chou YP, et al. Validation of chromogenic in situ hybridization for detection of EGFR copy number amplification in nonsmall cell lung carcinoma. Mod Pathol 2007;20:1028-1035.

38 Peters JH, Clark GW, Ireland AP, et al. Outcome of adenocarcinoma arising in Barrett's esophagus in endoscopically surveyed and nonsurveyed patients. J Thorac Cardiovasc Surg 1994;108:813-821; discussion 21-2.

39 Liu W, Hahn H, Odze RD, et al. Metaplastic esophageal columnar epithelium without goblet cells shows DNA content abnormalities similar to goblet cell-containing epithelium. Am J Gastroenterol 2009;104:816-824.

40 Hoff SJ, Sawyers JL, Blanke CD, et al. Prognosis of adenocarcinoma arising in Barrett's esophagus. Ann Thorac Surg 1998;65:176-180; discussion 80-1.

41 Romagnoli S, Roncalli M, Graziani D, et al. Molecular alterations of Barrett's esophagus on microdissected endoscopic biopsies. Lab Invest 2001;81:241-247.

42 Chandrasoma $\mathrm{P}$, Wickramasinghe $\mathrm{K}$, Ma $\mathrm{Y}$, et al. Is intestinal metaplasia a necessary precursor lesion for adenocarcinomas of the distal esophagus, gastroesophageal junction and gastric cardia? Dis Esophagus 2007;20:36-41.

43 Takubo K, Aida J, Naomoto Y, et al. Cardiac rather than intestinal-type background in endoscopic resection specimens of minute Barrett adenocarcinoma. Hum Pathol 2009;40:65-74.

44 James R, Erler T, Kazenwadel J. Structure of the murine homeobox gene cdx-2. Expression in embryonic and adult intestinal epithelium. J Biol Chem 1994;269: 15229-15237.

45 Silberg DG, Swain GP, Suh ER, et al. Cdx1 and cdx2 expression during intestinal development. Gastroenterology 2000;119:961-971.

46 Tsukamoto $\mathrm{T}$, Inada $\mathrm{K}$, Tanaka $\mathrm{H}$, et al. Downregulation of a gastric transcription factor, Sox2, and ectopic expression of intestinal homeobox genes, Cdx1 and Cdx2: inverse correlation during progression from gastric/intestinal-mixed to complete intestinal metaplasia. J Cancer Res Clin Oncol 2004; 130:135-145.

47 Almeida R, Silva E, Santos-Silva F, et al. Expression of intestine-specific transcription factors, CDX1 and CDX2, in intestinal metaplasia and gastric carcinomas. J Pathol 2003;199:36-40.

48 Phillips RW, Frierson Jr HF, Moskaluk CA. Cdx2 as a marker of epithelial intestinal differentia- tion in the esophagus. Am J Surg Pathol 2003;27: 1442-1447.

49 Villanacci V, Rossi E, Zambelli C, et al. COX-2, CDX2, and CDC2 immunohistochemical assessment for dysplasia-carcinoma progression in Barrett's esophagus. Dig Liver Dis 2007;39:305-311.

50 Washington $\mathrm{K}$, Chiappori A, Hamilton $\mathrm{K}$, et al. Expression of beta-catenin, alpha-catenin, and E-cadherin in Barrett's esophagus and esophageal adenocarcinomas. Mod Pathol 1998;11:805-813.

51 Zhou YN, Xu CP, Han B, et al. Expression of E-cadherin and beta-catenin in gastric carcinoma and its correlation with the clinicopathological features and patient survival. World J Gastroenterol 2002;8:987-993.

52 Bailey T, Biddlestone L, Shepherd N, et al. Altered cadherin and catenin complexes in the Barrett's esophagus-dysplasia-adenocarcinoma sequence: correlation with disease progression and dedifferentiation. Am J Pathol 1998;152:135-144.

53 Bian YS, Osterheld MC, Bosman FT, et al. Nuclear accumulation of beta-catenin is a common and early event during neoplastic progression of Barrett esophagus. Am J Clin Pathol 2000;114:583-590.

54 van Dekken H, Geelen E, Dinjens WN, et al. Comparative genomic hybridization of cancer of the gastroesophageal junction: deletion of 14Q31-32.1 discriminates between esophageal (Barrett's) and gastric cardia adenocarcinomas. Cancer Res 1999;59:748-752.

55 Jankowski J, McMenemin R, Hopwood D, et al. Abnormal expression of growth regulatory factors in Barrett's oesophagus. Clin Sci (Lond) 1991;81:663-668.

56 Jankowski J, Hopwood D, Wormsley KG. Flow-cytometric analysis of growth-regulatory peptides and their receptors in Barrett's oesophagus and oesophageal adenocarcinoma. Scand J Gastroenterol 1992;27: 147-154.

57 Brito MJ, Filipe MI, Linehan J, et al. Association of transforming growth factor alpha (TGFA) and its precursors with malignant change in Barrett's epithelium: biological and clinical variables. Int J Cancer 1995;60:27-32.

58 Ward EM, Wolfsen HC, Achem SR, et al. Barrett's esophagus is common in older men and women undergoing screening colonoscopy regardless of reflux symptoms. Am J Gastroenterol 2006;101:12-17.

59 Kelty CJ, Gough MD, Van Wyk Q, et al. Barrett's oesophagus: intestinal metaplasia is not essential for cancer risk. Scand J Gastroenterol 2007;42:1271-1274.

60 Spechler SJ, Fitzgerald RC, Prasad GA, et al. History, molecular mechanisms, and endoscopic treatment of Barrett's esophagus. Gastroenterology 2010;138: 854-869.

61 Eloubeidi MA, Desmond R, Arguedas MR, et al. Prognostic factors for the survival of patients with esophageal carcinoma in the US: the importance of tumor length and lymph node status. Cancer 2002;95:1434-1443.

62 Veldhuyzen van Zanten SJ, Thomson AB, Barkun AN, et al. The prevalence of Barrett's oesophagus in a cohort of 1040 Canadian primary care patients with uninvestigated dyspepsia undergoing prompt endoscopy. Aliment Pharmacol Ther 2006;23:595-599.

63 Bonhomme C, Duluc I, Martin E, et al. The Cdx2 homeobox gene has a tumour suppressor function in the distal colon in addition to a homeotic role during gut development. Gut 2003;52:1465-1471. 